\title{
Cardamonin Suppresses the Proliferation of Colon Cancer Cells by Promoting $\beta$-Catenin Degradation
}

\author{
Seoyoung Park, ${ }^{a}$ Jungsug Gwak, ${ }^{a}$ Seung Jin Han, ${ }^{b}$ and Sangtaek Oh*,a \\ ${ }^{a}$ Department of Advanced Fermentation Fusion Science \& Technology, Kookmin University; Seoul 136-702, Republic \\ of Korea: and ${ }^{b}$ Department of Biological Sciences, Inje University; Gimhae, Gyeongnam 621-749, Republic of Korea. \\ Received February 20, 2013; accepted March 23, 2013; advance publication released online March 29, 2013
}

\begin{abstract}
Aberrant accumulation of intracellular $\beta$-catenin and subsequent activation of $\beta$-catenin response transcription (CRT) in intestinal epithelial cells is a frequent early event during the development of colon cancer. Here we show that cardamonin, a chalcone isolated from Aplinia katsumadai HAYATA, inhibited CRT in $\mathrm{SW480}$ colon cancer cells that carry inactivating mutation in the adenomatous polyposis coli (APC) gene. Cardamonin also down-regulated intracellular $\beta$-catenin levels in SW480 cells without affecting its mRNA levels. Interestingly, pharmacological inhibition of the proteasome prevented the cardamonin-induced downregulation of $\beta$-catenin. In addition, cardamonin suppressed the expression of cyclin D1 and c-myc, which are known $\beta$-catenin/T cell factor (TCF)-dependent genes. Moreover, cardamonin inhibited the growth of various colon cancer cells and induced G2/M cell cycle arrest in SW480 colon cancer cells. These findings indicate that cardamonin is a potential chemotherapeutic agent against colon cancer.
\end{abstract}

Key words cardamonin; colon cancer; $\beta$-catenin; protein degradation

Wnt $/ \beta$-catenin signaling plays important role in cellular proliferation, morphology, motility, fate, axis formation, and organ development. ${ }^{1-3)}$ Intracellular $\beta$-catenin levels, which are regulated by phosphorylation-dependent proteasomal degradation, are key regulators of this signaling pathway. Casein kinase 1 (CK1) and glycogen synthase kinase-3 $\beta$ (GSK-3 $\beta$ ), which form a complex with the scaffolding protein Axin and the tumor suppressor protein adenomatous polyposis coli (APC), sequentially phosphorylate $\beta$-catenin at Ser45, Thr 41, Ser37, and Ser33. ${ }^{4,5)}$ Phosphorylated $\beta$-catenin is then recognized by the F-box $\beta$-transducin repeat-containing protein $(\beta$-TrCP), a subunit of the ubiquitin ligase complex, leading to its ubiquitin-dependent proteolysis. ${ }^{6,7)}$ Therefore, intracellular $\beta$-catenin is usually maintained at low levels in normal cells. However, in the presence of Wnt ligands, the activity of the CK1/GSK-3/APC/Axin destruction complex is negatively regulated; this results in the stabilization of cytoplasmic $\beta$-catenin.

Colorectal cancer is the most prevalent type of cancer and the second leading cause of cancer-related mortality in Western countries. ${ }^{8)}$ The association between aberrant $\mathrm{Wnt} / \beta$ catenin signaling and cancer, particularly colorectal cancer, has been well documented. ${ }^{9)}$ Mutations in the APC gene have been identified in patients with familial adenomatous polyposis coli (FAP) and sporadic colorectal tumors. ${ }^{10,11)}$ In addition, mutations in the $\beta$-catenin gene, affecting its $\mathrm{N}$-terminal phosphorylation motif, have been observed in patients with colorectal cancer. ${ }^{11)}$ These mutations result in $\beta$-catenin accumulation in the nucleus, where it forms a complex with members of the T-cell factor/lymphocyte enhancer factor (TCF/ LEF) transcription factor family. This leads to the enhanced expression of $\mathrm{Wnt} / \beta$-catenin-responsive genes, including cyclin D1, myc, matrix metalloproteinase-7, and peroxisome proliferator-activated receptor (PPAR)- $\delta$, which play important roles in colorectal tumorigenesis. ${ }^{12-15)}$ Thus, suppressing abnormally activated $\beta$-catenin response transcription (CRT) is a potential therapeutic approach for the chemoprevention and

The authors declare no conflict of interest. treatment of colon cancers

In the present study, we demonstrated that cardamonin significantly inhibits the Wnt/ $\beta$-catenin pathway by down-regulating intracellular $\beta$-catenin in colon cancer cells, thereby inducing $\mathrm{G} 2 / \mathrm{M}$ cell cycle arrest and suppressing the proliferation of colon cancer cells.

\section{MATERIALS AND METHODS}

Cell Cultures, Transfection, and Plasmids SW480, DLD-1, HCT116, and LS174T colon cancer cell lines were obtained from the American Type Culture Collection and maintained in Dulbecco's modified Eagle medium (DMEM) supplemented with $10 \%$ fetal bovine serum (FBS), $120 \mu \mathrm{g} / \mathrm{mL}$ penicillin, and $200 \mu \mathrm{g} / \mathrm{mL}$ streptomycin. Transfection was performed using Lipofectamine 2000 (Invitrogen, U.S.A.) according to the manufacturer's instructions. The cyclin D1 promoter region was amplified by polymerase chain reaction (PCR) and then inserted into a pRL-null reporter plasmid (Promega, U.S.A.). The pTOPFlash and pFOPFlash reporter plasmids were obtained from Upstate Biotechnology and the pCMV-RL plasmid was purchased from Promega.

Western Blotting Cytosolic fractions were prepared as described previously. ${ }^{16)}$ Whole lysates were prepared using NP40 lysis buffer. Proteins were separated by sodium dodecyl sulfate (SDS)-polyacrylamide gel electrophoresis in a $4-12 \%$ gradient gel (Invitrogen) and transferred to nitrocellulose membranes. The membranes were blocked using Odyssey blocking buffer (Li-Cor) and probed with anti- $\beta$-catenin (BD Transduction Laboratories), anti-cyclin D1, anti-c-myc (Santa Cruz Biotechnology), and anti-actin antibodies (Sigma). After washing with Tris-buffered saline plus Tween (TBS-T), the blots were incubated with flurorochrome-conjugated secondary antibodies, IRDye ${ }^{\circledR} 800 \mathrm{CW}$ Secondary Antibodies (LiCor). Membranes were then imaged using Odyssey Imaging System (Li-Cor).

RNA Extraction and Semiquantitative Reverse Transcription (RT)-PCR Total RNA was isolated using TRIzol reagent (Invitrogen) in accordance with the manufacturer's 
instructions. cDNA synthesis, reverse transcription, and PCR were performed as previously described. ${ }^{17)}$ Amplified DNA was mixed with Loading Star (DYNEBIO) and separated using $2 \%$ agarose gels.

Cell Viability Assay Cells were inoculated into 96-well plates and treated with cardamonin for $48 \mathrm{~h}$. Cell viability in each treated sample was measured in triplicate using the CellTiter-Glo assay kit (Promega), according to the manufacturer's instructions.

Cell Cycle Analysis SW480 cells were treated with cardamonin for $24 \mathrm{~h}$. Cells were then collected, washed with cold phosphate buffered saline (PBS), and fixed in 70\% ethanol at $4^{\circ} \mathrm{C}$ overnight. They were then centrifuged at $2000 \mathrm{rpm}$ for $5 \mathrm{~min}$, resuspended in $\mathrm{PBS}$, and incubated with propidium iodide $(100 \mu \mathrm{g} / \mathrm{mL})$ and RNase $\mathrm{A}(50 \mu \mathrm{g} / \mathrm{mL})$ at room temperature for $30 \mathrm{~min}$ in the dark. Cells were then analyzed using a FACSCalibur flow cytometer (Becton-Dickinson).

\section{RESULTS}

Cardamonin Induces $\boldsymbol{\beta}$-Catenin Down-Regulation in SW480 Colon Cancer Cells To investigate the effect of cardamonin, 2',4'-dihydroxy-6'-methoxychalcone (Fig. 1A), on CRT in colon cancer cells, SW480 colon cancer cells, which carry truncating mutations in the APC gene that cause constitutive activation of CRT, were transfected with TOPFlash plasmid, a synthetic $\beta$-catenin/Tcf-dependent firefly luciferase reporter. Treatment of the transfected SW480 cells with different concentrations of cardamonin produced a dose-dependent decrease in CRT (Fig. 1B). In contrast, cardamonin did not affect the activity of FOPFlash, a negative control reporter with mutated $\beta$-catenin/Tcf binding elements, in SW480 cells (Fig. 1B).

In $\mathrm{Wnt} / \beta$-catenin signaling, CRT is largely dependent on the level of intracellular $\beta$-catenin. Therefore, in order to assess whether cardamonin affects intracellular $\beta$-catenin levels, we performed western blot analysis using an anti- $\beta$-catenin antibody to quantify cytoplasmic $\beta$-catenin in cardamonintreated SW480 colon cancer cells. As shown in Fig. 1C, cardamonin down-regulated cytoplasmic $\beta$-catenin levels in a dose-dependent manner, which is consistent with results from reporter assay. These results suggest that cardamonin suppresses CRT by down-regulating intracellular $\beta$-catenin levels in SW480 colon cancer cells.

Cardamonin Promotes Proteasome-Mediated $\boldsymbol{\beta}$-Catenin Degradation Since cardamonin causes a reduction in the intracellular $\beta$-catenin level, we then examined whether cardamonin affects $\beta$-catenin mRNA levels using semiquantitative RT-PCR. In contrast with $\beta$-catenin protein levels, mRNA expression of $\beta$-catenin was not altered by any of the cardamonin concentrations used (Fig. 2A), suggesting that cardamonin inhibits the $\mathrm{Wnt} / \beta$-catenin pathway by down-regulation of $\beta$-catenin protein levels rather than repression of $\beta$-catenin gene expression. Previous studies have demonstrated that intracellular $\beta$-catenin levels are regulated by a proteasomal degradation pathway. ${ }^{18)}$ Therefore, we used MG-132, a proteasome inhibitor, to investigate the involvement of the proteasome in cardamonin-mediated $\beta$-catenin down-regulation. As shown in Fig. 2B, treatment of SW480 colon cancer cells with cardamonin consistently resulted in the down-regulation of cytoplasm $\beta$-catenin levels; however, the addition of
A<smiles>COc1cc(O)cc(O)c1C(=O)/C=C/c1ccccc1</smiles>

B

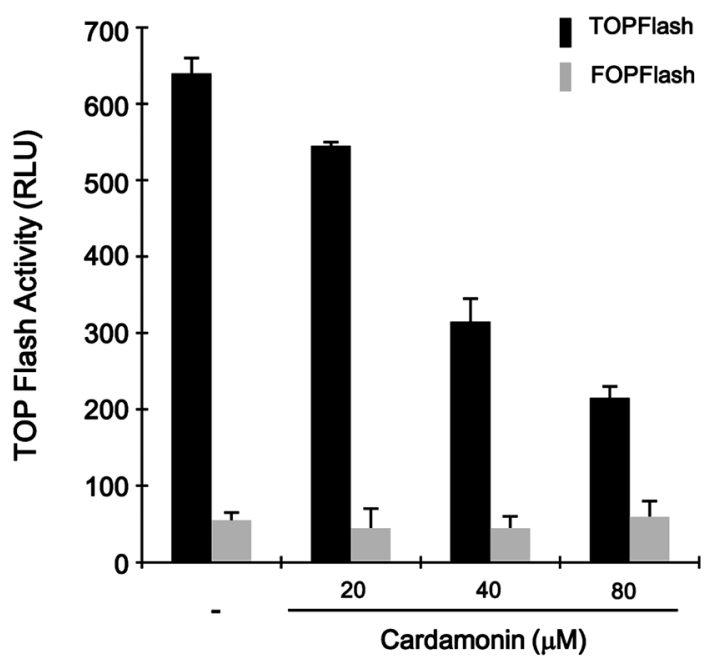

C

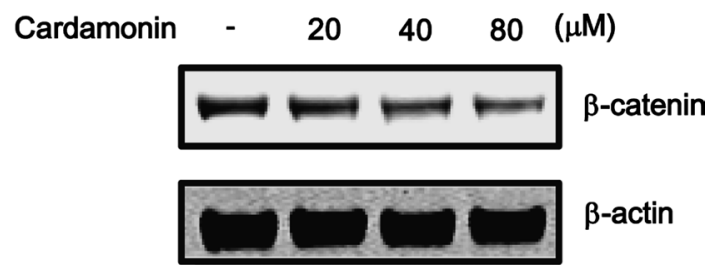

Fig. 1. Cardamonin Suppresses $\beta$-Catenin Response Transcription in SW480 Colon Cancer Cells

(A) Chemical structure of cardamonin. (B) SW480 cells were co-transfected with TOPFlash or FOPFlash and pCMV-RL plasmids and incubated with cardamonin $(20,40$, or $80 \mu \mathrm{M})$ for $15 \mathrm{~h}$. Luciferase activity was measured $39 \mathrm{~h}$ after transfection. TOPFlash or FOPFlash activity is expressed in relative light units (RLU), normalized to Renilla luciferase activity. Results represent the average of 3 experiments, and the bars indicate standard deviation. (C) Cytosolic proteins were isolated from SW480 cells treated with vehicle dimethyl sulfoxide (DMSO) or cardamonin (20, 40 , or $80 \mu \mathrm{M}$ ) for $15 \mathrm{~h}$ and were then analyzed by Western blotting using an anti$\beta$-catenin antibody. Blots were reprobed with anti-actin antibody to confirm equal loading.

MG-132 inhibited this cardamonin-mediated $\beta$-catenin downregulation. These results indicate that cardamonin induces proteasome-mediated degradation of intracellular $\beta$-catenin in SW480 cells.

Cardamonin Suppresses the Expression of $\boldsymbol{\beta}$-CateninDependent Genes Given that cardamonin down-regulate intracellular $\beta$-catenin levels, we then examined the effect of cardamonin on the expression of $\beta$-catenin-dependent genes in SW480 colon cancer cells. To this end, we transfected SW480 cells with a reporter construct, in which luciferase expres- 
A

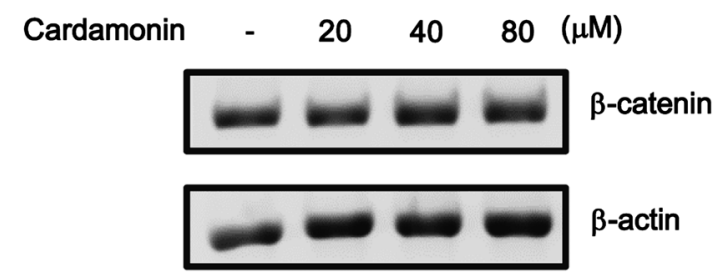

B

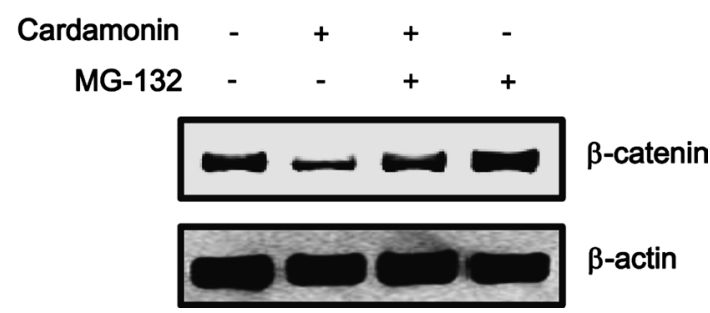

Fig. 2. Cardamonin Induces the Degradation of $\beta$-Catenin via a Proteasome Pathway

(A) Semiquantitative RT-PCR of $\beta$-catenin and glyceraldehyde-3-phosphate dehydrogenase was performed using total RNA prepared from SW480 cancer cells, treated for $15 \mathrm{~h}$ with either vehicle (DMSO) or cardamonin $(20,40$, or $80 \mu \mathrm{M})$. (B) Cytosolic proteins were prepared from SW480 cells that were incubated with vehicle (DMSO) or cardamonin $(80 \mu \mathrm{M})$, exposed to MG-132 $(10 \mu \mathrm{M})$ for $8 \mathrm{~h}$, and then analyzed by Western blotting using anti- $\beta$-catenin antibody. Blots were reprobed with anti-actin antibody as a loading control.

sion was controlled by the cyclin D1 promoter that contains a $\beta$-catenin/TCF-4 responsive region. The cells were then incubated with various concentrations of cardamonin. As shown in Fig. 3A, cardamonin inhibited cyclin D1 promoter activity in SW480 cells. We also examined cyclin D1 protein level in cardamonin-treated SW480 cells, and observed a dose-dependent decrease in these protein levels in response to cardamonin (Fig. 3B), which is consistent with our cyclin D1 promoter results. Moreover, the expression of c-myc, a known downstream target of $\beta$-catenin, was significantly reduced in SW480 colon cancer cells following incubation with cardamonin (Fig. 3B).

Cardamonin Inhibits Proliferation of Various Colon Cancer Cells Previous studies have reported that the specific disruption of $\beta$-catenin function by antisense oligonucleotides or small interference RNA suppresses the proliferation of cancer cells in vitro as well as tumor growth in a xenograft mouse model. ${ }^{19-22)}$ Since cardamonin promotes $\beta$-catenin degradation, we hypothesized that cardamonin also inhibits the growth of colon cancer cells. Therefore, we examined the effect of cardamonin on the proliferation of various colon cancer cells. As shown in Fig. 4A, cardamonin efficiently inhibited the growth of CRT-positive colon cancer cells (SW480, DLD-1, HCT116, and LS174T) in a concentration-dependent manner. We then investigated the possible mechanism responsible for inhibiting colon cancer cell growth in response to cardamonin by determining cell cycle distribution using propidium iodide staining followed by flow cytometry analysis. When SW480 cells were incubated with cardamonin, the population of cells in the $\mathrm{G} 2 / \mathrm{M}$ phase increased from $18.55 \%$ to $35.42 \%$ as compared with the vehicle control (Fig. 4B). These results suggest that cardamonin suppresses the growth of
A

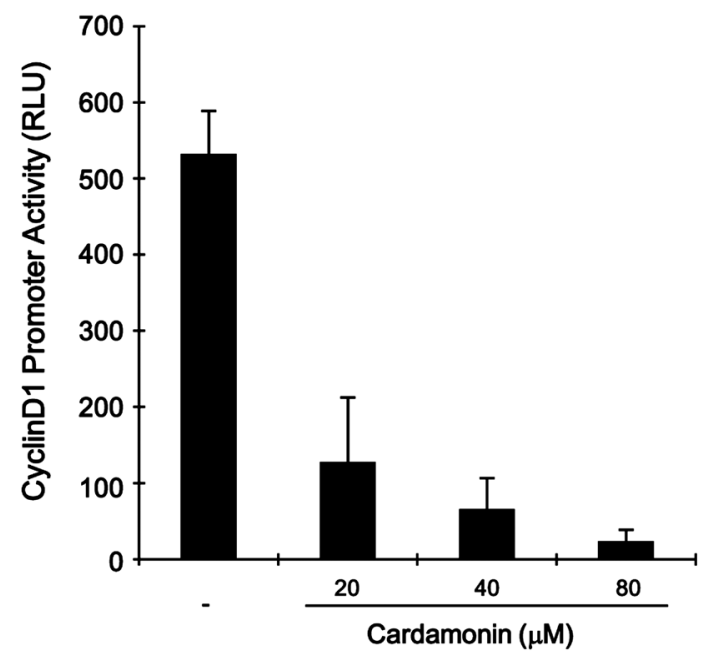

B

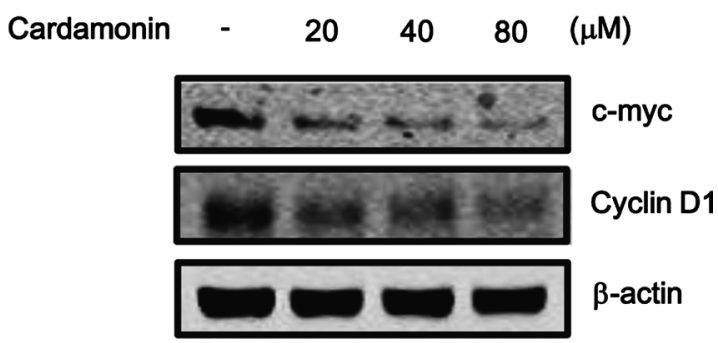

Fig. 3. Cardamonin Suppresses the Expression of $\beta$-Catenin Target Genes

(A) SW480 cells were co-transfected with cyclinD1-RL and pGL3 control, and then incubated with increasing cardamonin concentrations $(20,40$, or $80 \mu \mathrm{M})$ for $15 \mathrm{~h}$. Luciferase activity was measured $39 \mathrm{~h}$ after transfection. The results represent the average of 3 experiments, and the bars indicate standard deviation. (B) SW480 cells were incubated with vehicle (DMSO) or cardamonin $(20,40$, or $80 \mu \mathrm{M})$ for $15 \mathrm{~h}$. Whole-cell extracts was prepared and analyzed through Western blotting using anti-cyclin D1 antibody. Blots were reprobed with anti-actin antibody to confirm equal loading.

SW480 colon cancer cells by inducing G2/M cell cycle arrest.

\section{DISCUSSION}

Cardamonin exhibits anticancer properties by modulating cellular signal transduction pathways in several types of cancers. Qin et al. observed that cardamonin exerts preventive activity against multiple myeloma through blocking the nuclear factor-kappa B $(\mathrm{NF}-\kappa \mathrm{B})$ pathway. ${ }^{23)}$ Studies have also reported that cardamonin sensitizes tumor cells to tumor necrosis factor (TNF)-related apoptosis-inducing ligand (TRAIL) through CCAAT/enhancer binding protein homologous protein (CHOP)-mediated up-regulation of death receptor. ${ }^{24)}$ Additionally, Park et al. recently found that cardamonin inhibits the invasion of cancer cells by suppressing transglutaminase- 2 expression and inhibiting its activity. ${ }^{25)}$ In this study, we demonstrated, for the first time, that cardamonin suppresses the proliferation of colon cancer cells by promoting the degradation of intracellular $\beta$-catenin, which is abnormally accumulated in colon cancer cells.

Two APC-dependent pathways, an APC/Axin-dependent 
A

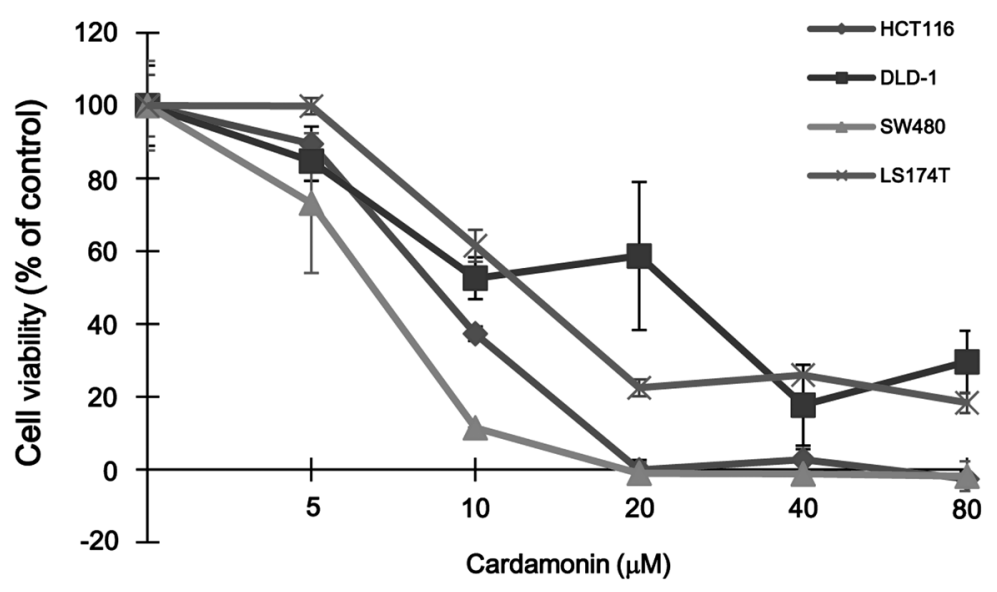

B
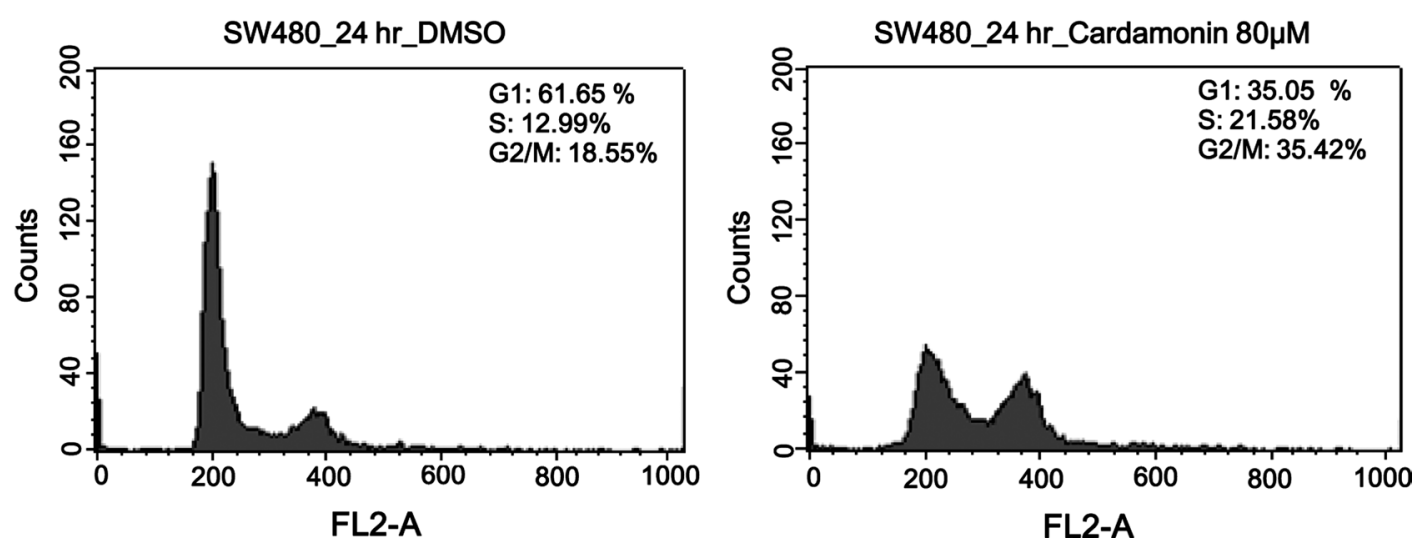

Fig. 4. The Effect of Cardamonin on Cell Growth

(A) Cells were incubated for $48 \mathrm{~h}$ in 96 -well plates with the indicated concentration of cardamonin. Cell viability was examined using the CellTiter-Glo assay (Promega). To calculate the inhibition of growth, the value at time 0 was subtracted. (B) SW480 cells were incubated with cardamonin $(80 \mu \mathrm{m})$ for $24 \mathrm{~h}$. After incubation, cells were harvested and stained with propidium iodide (PI), and then analyzed using a FACSCalibur flow cytometer. $x$-Axis indicates the PI fluorescence intensity that correlates with the DNA content.

pathway and an APC/Siah-1-dependent pathway, are predominantly involved in the regulation of $\beta$-catenin protein stability. In the APC/Axin-dependent pathway, the APC/Axin complex facilitates the CK1/GSK-3 $\beta$-mediated N-terminal phosphorylation of $\beta$-catenin, leading to its degradation. ${ }^{4,5)}$ In the APC/ Siah-1-dependent pathway, the carboxyl terminus of APC interacts with Siah-1, which recruits the ubiquitination complex and promotes the degradation of $\beta$-catenin. ${ }^{26)}$ On the other hand, the results of the present study showed that cardamonin promotes the degradation of $\beta$-catenin in SW480 cells, which are APC-mutant colon cancer cells, suggesting that APC is not required for $\beta$-catenin degradation by cardamonin. We will further investigate the mechanism of cardamonin-stimulated $\beta$-catenin degradation in future studies.

Several natural compounds that inhibit the function of pathogenic $\beta$-catenin have been identified. Curcumin, which is found in turmeric, was shown to induce the caspase3 -mediated cleavage of $\beta$-catenin ${ }^{27)}$ and its natural derivatives were shown to repress $\beta$-catenin response transcription (CRT) through down-regulation of the transcriptional coactivator p300. ${ }^{28)}$ Quercetin, a representative flavonol, was shown to suppress $\mathrm{Wnt} / \beta$-catenin signaling by reducing $\beta$-catenin and Tcf4 nuclear levels. ${ }^{29)}$ In this study, we found that cardamonin promotes intracellular $\beta$-catenin degradation through an APC-independent mechanism, and as a result suppresses the expression of cyclin D1 and c-myc, which play important roles in tumorigenesis and cell cycle progression.

In conclusion, we examined the anticancer effect of cardamonin on colon cancer cells, and we observed that cardamonin promotes the degradation of intracellular $\beta$-catenin, thereby inhibiting the proliferation of colon cancer cells. Therefore, our findings could facilitate the development of new chemopreventive or antineoplastic agents for colon cancer.

Acknowledgments This work was supported by the Basic Science Research Program (2012R1A2A2A01002941) and the Fundamental Technology Program (2012M3A9B2028335) through the National Research Foundation of Korea (NRF) funded by the Ministry of Education, Science and Technology. 


\section{REFERENCES}

1) Miller JR. The Wnts. Genome Biol., 3, reviews3001.1reviews3001.15 (2002).

2) Wodarz A, Nusse R. Mechanisms of Wnt signaling in development. Annu. Rev. Cell Dev. Biol., 14, 59-88 (1998).

3) Huelsken J, Birchmeier W. New aspects of Wnt signaling pathways in higher vertebrates. Curr. Opin. Genet. Dev., 11, 547-553 (2001).

4) Hart MJ, de los Santos R, Albert IN, Rubinfeld B, Polakis P. Downregulation of $\beta$-catenin by human Axin and its association with the APC tumor suppressor, $\beta$-catenin and GSK3 $\beta$. Curr. Biol., 8, 573-581 (1998)

5) Liu C, Li Y, Semenov M, Han C, Baeg GH, Tan Y, Zhang Z, Lin X, $\mathrm{He} X$. Control of $\beta$-catenin phosphorylation/degradation by a dualkinase mechanism. Cell, 108, 837-847 (2002).

6) Latres E, Chiaur DS, Pagano M. The human F box protein $\beta$-Trcp associates with the Cul1/Skp1 complex and regulates the stability of $\beta$-catenin. Oncogene, 18, 849-854 (1999).

7) Aberle H, Bauer A, Stappert J, Kispert A, Kemler R. $\beta$-Catenin is a target for the ubiquitin-proteasome pathway. EMBO J., 16, $3797-$ 3804 (1997).

8) Siegel R, Naishadham D, Jemal A. Cancer statistics, 2012. CA Cancer J. Clin., 62, 10-29 (2012).

9) Giles RH, van Es JH, Clevers H. Caught up in a Wnt storm: Wnt signaling in cancer. Biochim. Biophys. Acta, 1653, 1-24 (2003).

10) Fearnhead NS, Britton MP, Bodmer WF. The ABC of APC. Hum. Mol. Genet., 10, 721-733 (2001).

11) Morin PJ. $\beta$-Catenin signaling and cancer. Bioessays, 21, 1021-1030 (1999).

12) Tetsu O, McCormick F. $\beta$-Catenin regulates expression of cyclin D1 in colon carcinoma cells. Nature, 398, 422-426 (1999).

13) He TC, Sparks AB, Rago C, Hermeking H, Zawel L, da Costa LT, Morin PJ, Vogelstein B, Kinzler KW. Identification of c-MYC as a target of the APC pathway. Science, 281, 1509-1512 (1998).

14) Takahashi M, Tsunoda T, Seiki M, Nakamura Y, Furukawa Y. Identification of membrane-type matrix metalloproteinase-1 as a target of the $\beta$-catenin/Tcf4 complex in human colorectal cancers. Oncogene, 21, 5861-5867 (2002).

15) He TC, Chan TA, Vogelstein B, Kinzler KW. PPARdelta is an APCregulated target of nonsteroidal anti-inflammatory drugs. Cell, $\mathbf{9 9}$, 335-345 (1999)

16) Dignam JD, Lebovitz RM, Roeder RG. Accurate transcription initiation by RNA polymerase II in a soluble extract from isolated mammalian nuclei. Nucleic Acids Res., 11, 1475-1489 (1983).

17) Park S, Gwak J, Cho M, Song T, Won J, Kim DE, Shin JG, Oh S. Hexachlorophene inhibits $\mathrm{Wnt} / \beta$-catenin pathway by promoting Siah-mediated $\beta$-catenin degradation. Mol. Pharmacol., 70,
960-966 (2006).

18) Aberle H, Bauer A, Stappert J, Kispert A, Kemler R. $\beta$-Catenin is a target for the ubiquitin-proteasome pathway. EMBO J., 16, 37973804 (1997).

19) Roh H, Green DW, Boswell CB, Pippin JA, Drebin JA. Suppression of $\beta$-catenin inhibits the neoplastic growth of APC-mutant colon cancer cells. Cancer Res., 61, 6563-6568 (2001).

20) Verma UN, Surabhi RM, Schmaltieg A, Becerra C, Gaynor RB Small interfering RNAs directed against $\beta$-catenin inhibit the in vitro and in vivo growth of colon cancer cells. Clin. Cancer Res., 9, 1291-1300 (2003).

21) Green DW, Roh H, Pippin JA, Drebin JA. $\beta$-Catenin antisense treatment decreases $\beta$-catenin expression and tumor growth rate in colon carcinoma xenografts. J. Surg. Res., 101, 16-20 (2001).

22) Foley PJ, Scheri RP, Smolock CJ, Pippin J, Green DW, Drebin JA. Targeted suppression of $\beta$-catenin blocks intestinal adenoma formation in APC Min mice. J. Gastrointest. Surg., 12, 1452-1458 (2008).

23) Qin Y, Sun CY, Lu FR, Shu XR, Yang D, Chen L, She XM, Gregg NM, Guo T, Hu Y. Cardamonin exerts potent activity against multiple myeloma through blockade of $\mathrm{NF}-\kappa \mathrm{B}$ pathway in vitro. Leuk. Res., 36, 514-520 (2012).

24) Yadav VR, Prasad S, Aggarwal BB. Cardamonin sensitizes tumour cells to TRAIL through ROS- and CHOP-mediated up-regulation of death receptors and down-regulation of survival proteins. $\mathrm{Br} . \mathrm{J}$. Pharmacol., 165, 741-753 (2012).

25) Park MK, Jo SH, Lee HJ, Kang JH, Kim YR, Kim HJ, Lee EJ, Koh JY, Ahn KO, Jung KC, Oh SH, Kim SY, Lee CH. Novel suppressive effects of cardamonin on the activity and expression of transglutaminase-2 lead to blocking the migration and invasion of cancer cells. Life Sci., 92, 154-160 (2013).

26) Liu J, Stevens J, Rote CA, Yost HJ, Hu Y, Neufeld KL, White RL, Matsunami N. Siah-1 mediates a novel $\beta$-catenin degradation pathway linking p53 to the adenomatous polyposis coli protein. $\mathrm{Mol}$. Cell, 7, 927-936 (2001).

27) Jaiswal AS, Marlow BP, Gupta N, Narayan S. $\beta$-Catenin-mediated transactivation and cell-cell adhesion pathways are important in curcumin (diferuylmethane)-induced growth arrest and apoptosis in colon cancer cells. Oncogene, 21, 8414-8427 (2002).

28) Ryu MJ, Cho M, Song JY, Yun YS, Choi IW, Kim DE, Park BS, Oh S. Natural derivatives of curcumin attenuate the $\mathrm{Wnt} / \beta$-catenin pathway through down-regulation of the transcriptional coactivator p300. Biochem. Biophys. Res. Commun., 377, 1304-1308 (2008).

29) Park CH, Chang JY, Hahm ER, Park S, Kim HK, Yang CH. Quercetin, a potent inhibitor against $\beta$-catenin/Tcf signaling in SW480 colon cancer cells. Biochem. Biophys. Res. Commun., 328, 227-234 (2005). 